\title{
AÇÕES FORMATIVAS (INSTITUCIONAIS) PARA A DOCÊNCIA NO ENSINO SUPERIOR NAS UNIVERSIDADES PÚBLICAS FEDERAIS BRASILEIRAS
}

TRAINING ACTIONS (INSTITUTIONAL) FOR TEACHING IN HIGHER EDUCATION IN BRAZILIAN FEDERAL PUBLIC UNIVERSITIES

\section{ACCIONES FORMATIVAS (INSTITUCIONALES) PARA LA DOCENCIA EN EDUCACIÓN SUPERIOR EN UNIVERSIDADES PÚBLICAS FEDERALES BRASILEÑAS}

Judilma Aline Oliveira Silva ${ }^{1}$

\section{RESUMO}

$\mathrm{O}$ artigo trata da síntese da tese, desenvolvida no Programa de Pós-Graduação em Educação (PPGE), da Universidade Federal de Juiz de Fora (UFJF), investigou: como as Instituições de Ensino Superior (IES), especificamente as Universidades Públicas Federais Brasileiras, estão desenvolvendo ações institucionais voltadas à formação dos docentes, e de que forma a cultura digital está integrada a esses processos formativos? O objetivo foi mapear, no Brasil e nas Universidades Públicas Federais, os programas institucionais voltados para a formação docente. A base teórica fundamenta-se em Masetto (2015), Zabalza (2004), Nóvoa (2016), Pimenta e Anastasiou (2010), entre outros. A opção metodológica encontrou na fenomenologia a inspiração epistemológica para a produção dos dados e a compreensão dos significados produzidos pelas IES. O campo foi: a) aplicação de questionário, em 2016; b) entrevistas em seis IES de uma amostra de dez selecionadas, em 2017/2018; c) entrevistas com três IES, em 2018, das dez que haviam participado de um projeto piloto, em 2014. Percebeu-se que os processos formativos para as docências no Ensino Superior estão em crescimento, ainda que pesem situações de extinção do setor encarregado para tal e/ou incorporação das atividades por outro setor. Ressalta-se uma devolutiva de $70 \%$ das IES pesquisadas e os resultados sinalizaram avanços nas ofertas formativas propostas pelas instituições, ênfase na perspectiva instrumental quanto aos usos das TIC, com integração de recursos tecnológicos nos cursos, em detrimento de uma perspectiva culturalista. Existem boas possibilidades de incorporação da cultura digital, faz-se necessário estabelecer uma

Submetido em: 10/06/2020 - Aceito em: 28/11/2020 - Publicado em: 24/12/2020

\footnotetext{
${ }^{1}$ Pedagoga, Mestre e Doutora em Educação pela Universidade Federal de Juiz de Fora; Professora Substituta da UFSJ e da Faculdade Machado Sobrinho em Juiz de Fora. Atua como tutora do Curso de PedagogiaUAB/UFJF, como avaliadora In loco do Inep/MEC e, membro do Grupo de Pesquisa Aprendizagem em RedeGRUPAR/UFJF.
} 
cultura institucional que reconheça e valorize a prática pedagógica dos docentes universitários.

PALAVRAS-CHAVE: Docentes da Educação Superior. Formação Continuada. Cultura digital.

\begin{abstract}
The article deals with the synthesis of the thesis, developed in the Graduate Program in Education (PPGE), of the Federal University of Juiz de Fora (UFJF), investigated: how Higher Education Institutions (IES), specifically the Brazilian Federal Public Universities, are developing institutional actions aimed at training teachers, and how is digital culture integrated into these training processes? The objective was to map, in Brazil and in the Federal Public Universities, the institutional programs aimed at teacher education. The theoretical basis is based on Masetto (2015), Zabalza (2004), Nóvoa (2016), Pimenta and Anastasiou (2010), among others. The methodological option found in phenomenology the epistemological inspiration for the production of data and the understanding of the meanings produced by the HEIs. The field was: a) application of a questionnaire in 2016; b) interviews in six HEIs from a sample of ten selected; c) interviews with three HEIs out of the ten who had participated in a pilot project in 2014. It was noticed that the training processes for teaching in Higher Education are growing, even though the sector responsible for such and / or incorporation of activities by another sector. It should be noted that $70 \%$ of the researched HEIs returned, and the results signaled advances in the training offers proposed by the institutions, with an emphasis on the instrumental perspective regarding the uses of ICT, with the integration of technological resources in the courses, to the detriment of a culturalist perspective. There are good possibilities for incorporating digital culture, it is necessary to establish an institutional culture that recognizes and values the pedagogical practice of university teachers.

Elaborar um resumo informativo contendo de 100 a 250 palavras, mantendo a estrutura das seções aqui colocadas em negrito.
\end{abstract}

KEYWORDS: Higher Education Teachers. Continuing Education. Digital culture.

\title{
RESUMEN
}

El artículo trata de la síntesis de la tesis, desarrollada en el Programa de Posgrado en Educación (PPGE), de la Universidad Federal de Juiz de Fora (UFJF), investigada: cómo las Instituciones de Educación Superior (IES), específicamente las Universidades Públicas Federales de Brasil, ¿se están desarrollando acciones institucionales orientadas a la formación de docentes, y cómo se integra la cultura digital en estos procesos formativos? El objetivo fue mapear, en Brasil y en las Universidades Públicas Federales, los programas institucionales dirigidos a la formación docente. La base teórica se basa en Masetto (2015), Zabalza (2004), Nóvoa (2016), Pimenta y Anastasiou (2010), entre otros. La opción metodológica encontró en la fenomenología la inspiración epistemológica para la producción de datos y la comprensión de los significados producidos por las IES. El campo fue: a) aplicación de un cuestionario en 2016; b) entrevistas en seis IES de una muestra de diez seleccionadas; c) entrevistas a tres IES de las diez que habían participado en un proyecto piloto en 2014. Se notó que los procesos de formación para la docencia en Educación Superior están creciendo, aunque el sector responsable de tal y / o incorporación de actividades por otro sector. Cabe señalar que el $70 \%$ de las IES investigadas retornaron, y los resultados señalaron avances en las ofertas formativas propuestas por las instituciones, con énfasis en la perspectiva instrumental sobre los usos de las TIC, con la integración de los recursos tecnológicos en los cursos, en detrimento de una perspectiva culturalista. Existen buenas posibilidades para incorporar la cultura digital, es necesario establecer una cultura institucional que reconozca y valore la práctica pedagógica de los docentes universitarios.

PALABRAS CLAVE: Docentes de educación superior. Educación continua. Cultura digital . 


\section{INTRODUÇÃO: apresentação da temática e síntese dos capítulos}

Esta síntese acaba de ser escrita um ano e seis meses após a defesa da tese realizada em 25/02/2019. Dizem por aí que quando encerramos um doutorado precisamos de um tempo sem "pegar" na tese, de decantação, enquanto tentamos reequilibrar nossas forças e energias. Isso porque é um trabalho árduo, ainda que prazeroso, de persistência e perseverança, apesar da confiança da conclusão ser sempre uma dúvida constante. Por isso, tal premissa deve ser verdadeira porque quando eu estava prestes a iniciar essa escrita, que ora apresento, o mundo foi surpreendido com uma pandemia, no Brasil revelada a partir de março deste ano, provocada pelo denominado COVID-19.

Vale dizer que ainda estamos sobrevivendo a uma pandemia, com todos os percalços afeitos a este momento que, direta ou indiretamente, nos abala. No entanto, ainda que esse contexto seja complexo e adverso, a produção acadêmica/científica não parou e por isso, trazer a tona os resultados desta pesquisa de tese nos ajuda a refletir sobre a realidade que a pandemia colocou em evidência: a formação dos docentes e a questão das Tecnologias Digitais de Informação e Comunicação (TDIC). Ainda que a pesquisa desenvolvida tenha tido como foco as Universidades Públicas Federais do Brasil, é possível vislumbrar semelhanças dos dados com o cenário atual da educação brasileira. Isso porque os dados refletem a realidade vivenciada por grande parte das Instituições de ensino, sejam públicas ou privadas, e corrobora com a dificuldade constatada pelos docentes no que diz respeito a apropriação das TDIC junto a sua prática pedagógica.

As redes, que se faziam presentes antes do evento da pandemia COVID-19, atualmente se apresentam como imprescindíveis para que as docências ocorram. As aulas passam a ser ressignificadas, tendo seus sentidos e significados ampliados e potencializados, em meio aos 
dispositivos digitais. Mas se as aulas passam a se dar também em plataformas e em AVA, os apelos por processos formativos para docências online emergem com muita força. Debates sobre Educação a distância, temporalidades no online, desenhos didáticos, recursos e instrumentos para aulas a distância tanto por meio remoto quanto via rádio, TV e impresso se tornam constantes no cotidiano de docentes. Tal cenário nos mostra que as mudanças no campo da educação são inevitáveis e, ainda que os processos formativos no Ensino Superior não tenha ocorrido como desejado, a "guerra contra o virus" poderá promover a tão desejada mudança na educação.

A pandemia evidenciou diversos cenários no contexto da educação brasileira e destacamos o da formação dos docentes que atuam em Instituições públicas. A realidade da Instituição pública, que por sua natureza recebe públicos diversos, com padrões socioeconômicos variados, é sensível e atenta a questão da inclusão. Por conta disso, muitas destas ainda estão sem ofertar o ensino tendo em vista a necessidade real de conhecer e saber se de fato todos os seus alunos e professores possuem as condições mínimas para um tipo de ensino que não seja presencial. É preciso entender que o docente precisa conhecer minimamente não só os artefatos tecnológicos necessários para o desenvolvimento de uma prática docente mas, também, as questões pedagógicas que envolvem a mediação e a apropriação dos conteúdos em ambientes virtuais de aprendizagem.

Destarte, a referida pesquisa partiu da seguinte questão: Como as Instituições de Ensino Superior (IES), especificamente as Universidades Públicas Federais Brasileiras, estão desenvolvendo ações institucionais voltadas à formação dos docentes, e de que forma a cultura digital está integrada a esses processos formativos? Teve como objetivo Geral: Mapear, junto a todas as Universidades federais brasileiras, a existência de programas institucionais para a formação docente por elas promovido, a fim de compreender seus processos e ações formativas e em que medida faz uso das TIC, como interface pedagógica. Já os objetivos específicos foram: verificar, por meio do mapeamento, o número de IES que 
já realizavam as ações de formação e de capacitação dos docentes, no período compreendido entre 2012 e $2016^{2}$; realizar uma análise mais detalhada dos projetos institucionais voltados à introdução e inclusão das TIC, com interface pedagógica; identificar a percepção do gestor ${ }^{3}$ em relação aos processos formativos desenvolvidos na Universidade; realizar uma análise crítica dos projetos institucionais voltados à introdução e difusão do uso das TIC como interface pedagógica.

Espero contribuir para o momento atual corroborando com a discussão de que a formação docente se faz imprescindível e necessária para atravessar qualquer contexto, ainda que estejamos vivenciando um momento único e singular da nossa história. Isso porque são esses os profissionais capazes em prover um ensino que não seja distante, que tenha afeto e seja significativo e, para tal, independe do espaço que habita (físico ou virtual) desde que entenda das estratégias metodológicas e didáticas para poder transitar nesses espaços, conseguirá o protagonismo da história. Que tenhamos formações adequadas e capazes de proporcionar resultados significativos para todos os envolvidos.

Dito isso, apresento a estrutura desenvolvida na tese $\mathrm{C}^{4}$. No primeiro capítulo, o levantamento bibliográfico realizado por meio de uma revisão da literatura, na qual, além dos achados encontrados sobre formação docente, foi produzido um diálogo com o referencial teóricometodológico fundamentado em autores como Zabalza (2004, 2005), Masetto (2015), Nóvoa (1995, 1999, 2016) e Pimenta e Anastasiou (2010). Ainda neste capítulo, à luz de teóricos Chauí (2001, 2003), Cunha (2000), Fávero (2006), entre outros, um aprofundamento, cujo foco relaciona-se desde o surgimento das Universidades brasileiras até a forma como trataram a formação do docente universitário.

\footnotetext{
${ }^{2}$ A escolha desse período se deve ao fato de que, a partir da Lei de 2012, sobre Plano de Carreira e Cargos, foram incluídas ações de acolhimento para os docentes. Já o recorte final, 2016, refere-se ao ano de ida a campo.

${ }^{3}$ Optei em utilizar "gestor" para a pessoa que é responsável, na Universidade, por toda a estrutura dos programas e/ou ações que são realizadas. Esse sujeito tanto pode vir a ser um professor ou um técnico administrativo - TAE em educação.

${ }^{4}$ A tese está disponível na íntegra no site do PPGE/UFJF, vide: https://www.ufjf.br/ppge/files/2019/03/TESEFINAL-Revisada-em-11-5-19-FORMATADA-FINAL-ok.pdf
} 
Assim, além de utilizar autores clássicos que abordam seja a formação docente, seja a relação das Universidades com essa formação, buscamos em recentes teses e dissertações compreender esta temática. Entre algumas, citamos apenas as pesquisas realizadas por Bazzo (2007), Pachane (2003), Vasconcelos (2011) e Souza (2012), as quais, além da relevância do trabalho, apresentam recortes que dialogam com os mesmos autores do meu referencial teórico, sendo essa convergência fundamental na escolha dos referidos trabalhos.

No segundo capítulo, trabalhamos a questão da cultura digital na formação e na prática no ensino superior: com o objetivo de mostrar de que forma a tecnologia se fazia presente nas ações e práticas pedagógicas, tivemos como foco abordar como era percebida a cultura digital, nas ações de formação desenvolvidas pelas IES. Para construção deste capítulo, alguns dos autores consultados: Santaella (2003, 2004), Lemos (2009), Lévy (2009), entre outros, que auxiliaram a pensar como a cultura digital tem sido incorporada no cotidiano das pessoas e, consequentemente, nos espaços das Universidades Públicas Federais.

No terceiro capítulo, a entrada no campo de pesquisa. Vale ressaltar que esta parte foi retratada em três momentos distintos e por meio de dois instrumentos de pesquisa: questionário e entrevistas. No primeiro momento, o resultado da aplicação dos questionários, realizados em 2016, quando foi possível trazer um mapeamento de todas as IES contatadas para a pesquisa. No segundo momento, as entrevistas realizadas com o recorte das IES que já haviam respondido ao questionário e se dispuseram a participar de um novo momento, realizado em 2017 e início de 2018. Por fim, no último momento, o resultado das entrevistas aplicadas para as IES que já haviam participado de um projeto piloto em 2014 e, quatro anos após, em 2018, quando participaram deste novo momento.

Por fim, nas considerações finais foram apresentadas sugestões e alguns apontamentos amparados nas leituras e nos dados produzidos com a pesquisa de campo. Ainda que esta 
síntese represente de forma enxuta todo o trabalho desenvolvido, esperamos que seja capaz de mostrar toda a sua densidade e singularidade.

\section{E os dados revelam...}

O percurso desenvolvido leva a sugerir alguns apontamentos amparados nas leituras e nos dados apresentados com a pesquisa de campo. Trago um recorte dos dados obtidos e o que eles nos revelam. Coerente com a inspiração metodológica escolhida, não há conclusões, mas uma construção de resultados, posto que, não sendo encarceráveis, as compreensões nunca serão definitivas, como ressalta Garnica (1997).

No capítulo sobre as Instituições de Ensino Superior Público e Federal foi apresentada a Lei 12772/2012 que orienta as instituições públicas de ensino superior à realização de ações para acolhimento do docente, em período probatório. Era de se esperar que todas as IES estivessem seguindo esta normativa e promovendo ações formativas, só que há sobre esse ponto uma contradição e, concomitantemente, uma indagação. O que dizer quando os dados mostram que ainda há, no Brasil, instituições que ignoraram tal prerrogativa legal? Mesmo que o número dessas instituições seja menor que $10 \%$, elas existem e não cumprem o que é recomendado por Lei. Mesmo que a Lei seja de 2012 e a pergunta tenha sido feito em 2016, ainda não havia ocorrido alteração. É preciso considerar o contexto em que muitas dessas Instituições estavam atravessando e que envolvia questões políticas. A pesquisa foi capaz de identificar que no ensino superior vivemos a transição da cultura do professor sabe-tudo, doutrinário, cujas práticas pedagógicas são centradas na reprodução linear dos conteúdos, para o docente que vive e produz cultura digital. Esse fato tem mais uma vez explicitado as demandas de formação do professor universitário e que, no momento atual com a pandemia, tornou-se ainda mais evidente. 
Deve-se ter claro que instituir ações de formação docente num espaço como as Universidades Públicas já poderia ser compreendida como espécie de rompimento com a ideia de que a formação do pesquisador stricto sensu já seria suficiente para tais atos pedagógicos. Entretanto, sabemos que formar/tornar-se professor/a implica assumir uma educação emancipadora.

Um dado que foi possível verificar em dois momentos da pesquisa diz respeito à questão do acompanhamento após a realização das ações de formação pelas Universidades. No mapeamento inicial, em 2016, foi constatado que $71 \%$ das instituições não realizavam quaisquer ações de acompanhamento do docente que participou das ações de formação continuada durante o período probatório. No segundo momento da pesquisa, com a entrevista, quando foi questionado sobre ações de acompanhamento, foi constatado que metade das IES já realizava ações de avaliação logo após o encerramento do curso. É preciso considerar que desenvolver programas de tal magnitude e que envolve um quantitativo alto de pessoas, não seja uma tarefa simples e comum de se realizar. Soma-se a isso a questão de que os professores estão sempre atuando em diversas disciplinas.

Outro ponto relevante foi verificar que mais de $70 \%$ das IES realizam ações de formação envolvendo as TIC - que são feitas presencialmente e a distância. Isso sinaliza que o caminho em prol da apropriação do conhecimento já se faz muito presente. Esse dado confirma a posição de alguns autores citados ao longo deste trabalho segundo os quais o caminho para uma docência atual deve ser permeado pelo uso e pela incorporação das TIC. Assim, a formação no e pelo digital passa a ser atributo imprescindível à promoção de práticas pedagógicas atrativas para os alunos imbricados e imersos na cultura digital.

Percebo que, ao tratar o tema formação docente universitária, não há um consenso entre os autores pesquisados sobre o que é necessário para tal formação. Enquanto alguns trabalham com o termo habilidade e, dessa forma, listam uma série delas, como as apropriações das TIC, 
que são necessárias ao docente, outros apontam o termo saberes para justificar quais são os fundamentais. Além disso, há ainda carência na formação dos docentes no ensino superior para incorporação - letramento digital ${ }^{5}$ - das TIC em suas aulas.

Para tensionar ainda mais esse campo da formação docente universitária, resgato Vasconcellos e Sordi (2016, p 412), quando citam os principais desafios a serem enfrentados pelos programas de formação:

[...] a luta constante na resistência às políticas reguladoras que caminham na contramão de uma educação que vise uma qualidade social; a concretização de políticas institucionais que garantam a consolidação e continuidade de tais programas, independente dos atores que os defendem e os estruturam atualmente, e a valorização de uma formação pedagógica universitária baseada em princípios éticos e políticos de emancipação humana. Uma estratégia a ser priorizada, com vistas ao enfrentamento dos desafios postos, e que queremos enfatizar, é a construção de redes de articulação entre os programas existentes, visando, além de trocas de experiências, uma aprendizagem colaborativa e uma formação compartilhada, que prime pelo fortalecimento dos grupos e constituição de políticas institucionais.

$\mathrm{O}$ ponto em destaque ressalta a importância das redes que se constituem e que algumas Instituições já apontaram como uma alternativa para suprir parte de suas demandas. Seja por meio de ações entre pares, seja por conta do corte de orçamento e que inviabilizou a manutenção de eventos com convidados externos a Instituição.

Outro dado que a tese evidenciou diz respeito a questão dos editais para concurso público. Se a atividade fim de um concurso para ingresso na carreira de professor universitário é a docência, os editais não precisariam contemplar de forma mais efetiva a prática docente? Será apenas o uso de uma prova aula ou didática o suficiente para analisar os aspectos pedagógicos? A quem cabe intervir neste ponto? O estudo mostrou que em muitos programas há em curso ajustes, seja em relação a atribuição de pontos (com peso maior para a prova didática) seja na valorização de memoriais buscando conhecer a trajetória do candidato. Essas

\footnotetext{
${ }^{5}$ Vale ressaltar que, ao logo deste trabalho, ocorreu a explicação e a diferenciação no que diz respeito ao termo letramento digital.
} 
modificações poderão a médio e/ou a longo prazo vir a obter candidatos cuja trajetória acadêmica na docência seja, de fato, valorizada.

Outro ponto diz respeito ao quantitativo de programas institucionais de formação docente. Segundo Veiga; et al. (2012, p. 13): [...] temos que admitir que um número muito pequeno de IES possui um Programa de Formação institucionalizado para promover o desenvolvimento profissional docente". O dado apresentado pela autora sofreu mudanças, como é evidenciado em minha pesquisa, que computa avanço significativo, num espaço de seis anos: contabilizei 70\% das Universidades Públicas Federais do Brasil, ou seja, das 37 IES pesquisadas, 31 delas (86\%) já desenvolvem ações de formação continuada junto aos seus docentes. No entanto, há de se destacar que a prática de pesquisar as próprias ações vem ocorrendo de forma lenta. Entre os dois momentos desta investigação, três Universidades investiram nesse tipo de produção.

Se há avanços no aspecto quantitativo, reforço um alerta proferido por Nóvoa (1999), ao falar sobre os programas formativos, em que afirmou que estes precisam acontecer articulados com os demais aspectos do desenvolvimento profissional, caso contrário, acabarão sendo mais uma sobrecarga imposta aos docentes, que já estão sobrecarregados de demandas. É necessário valorizar "a sistematização dos saberes próprios, a capacidade para transformar a experiência em conhecimento e a formalização de um saber profissional de referência" (NÓVOA, 1999, p. 20).

Temos que pensar no futuro dos professores sim, mas não podemos desconsiderar o presente e muito menos negar a indignação com o estado atual. Será que não é chegado o momento de rever o Artigo 66 da Lei 9394/96, que situa a formação docente como preparo para o exercício do magistério superior em nível de Pós-Graduação? Onde entra a formação pedagógico-didática para esses docentes? Essas indagações, ainda sem respostas, se tornam ainda mais fortes no contexto atual. 
Assim, com intuito de finalizar esta síntese, voltamos à questão norteadora desta pesquisa: Como as Instituições de Ensino Superior (IES), especificamente as Universidades Públicas Federais Brasileiras, estão desenvolvendo ações institucionais voltadas para a formação dos docentes, e de que forma a cultura digital está integrada a estes processos formativos? - é preciso recorrer ao questionário e às entrevistas e assim, é possível dizer que:

a) Os tipos de ações de formação são diversos: em algumas IES, não há política clara sobre formação, tampouco política institucional;

b) A maioria das IES pesquisadas admite que há necessidade constante por ações de formação;

c) No primeiro mapeamento (2016), o tipo de ação predominante era palestra, e no segundo, com as entrevistas, foi possível perceber que o foco mudou para cursos com carga horária maior que as palestras;

d) Ainda sobre esse mapeamento, na visão dos gestores, 70\% dos docentes estão com práticas defasadas em sala de aula;

e) Todas as IES que realizam diagnóstico para identificar demandas conseguem obter maior adesão de participação dos docentes;

f) As demandas de práticas para sala de aula têm sido destaque nas formações;

g) A cultura digital é gradual nas ações de formação por meio dos tipos de ações que têm sido ofertadas;

h) Em todas as etapas desta pesquisa, as formações ocorrem majoritariamente de forma online e todas as Universidades possuem AVA que promovem as ações formativas.

i) Os tipos de ações têm sido afetados pela crise institucional que muitas IFES têm sofrido recentemente com a política de recessão econômica, impactando diretamente todos os setores, inclusive na formação docente, quando a Universidade ainda oferece.

j) No primeiro momento da pesquisa (2016), a maioria que respondeu ao questionário (12 em 20 IES) possuía um setor específico para cuidar da formação seja em forma de núcleo, coordenação e/ou diretoria; já no segundo momento (2018), das seis 
entrevistadas, apenas em uma IES o setor deixou de existir, e as demandas sobre formação docente foram incorporadas pela Pró-Reitoria de Gestão de Pessoas.

k) As publicações voltadas para a docência no ensino superior correspondem a $36 \%$, enquanto as da educação básica, 64\%, segundo o mapeamento realizado em 2015.

Assim, acredito que as vivências relatadas nesta tese sinalizam a possibilidade de uma práxis formativa institucional rumo à cultura digital e pedagógica dos docentes universitários. Diante deste contexto, insere-se uma indagação: estamos caminhando, como apregoa a pesquisadora Almeida (2012), para uma concepção ecológica sobre a formação docente, que poderá culminar em uma nova cultura profissional?

Por fim, o que foi possível perceber é que não há evidências de que os cursos formativos estão numa perspectiva culturalista, mas instrumentalista, de forma que são feitos para o uso sem a percepção crítica. Ainda assim, será necessário incorporar nas ações formativas elementos que favoreçam a compreensão de que, no mundo atual, é necessária a cultura das mídias digitais, sem cujo domínio estaremos fadados ao obscurantismo.

Acredito que este estudo poderá contribuir para todos que estejam pesquisando o tema formação docente. Nenhuma pesquisa mapeou $70 \%$ das ações institucionais formativas que estão sendo realizadas pelas Universidades Públicas Federais para a docência. Todos os trabalhos encontrados na revisão da literatura restringiam-se a situações específicas e/ou pontuais.

Espero que ações formativas sejam fonte de inspiração para gestores e, principalmente, professores com forças para buscar sempre sua formação, e que sejam capazes de prover e reelaborar sua prática profissional e sua capacidade de inovar, renovar e viver a docência com toda sua energia vital. Acredito que esse seja um campo fértil para o investimento em ações 
formativas e em pesquisas, tendo em vista que há poucas publicações sobre o tema, comparando-se com a formação do professor da educação básica.

\section{REFERÊNCIAS ${ }^{6}$}

ALMEIDA, Maria Isabel de. Formação do professor do ensino superior: desafios e políticas institucionais. São Paulo: Cortez, 2012.

BAZZO, Vera Lúcia. Constituição da professoralidade docente na educação superior: desafios e possibilidades. Tese (Doutorado) - Faculdade de Educação, Universidade Federal do Rio Grande do Sul, 2007.

Brasil. Lei 12 772, de 28 de dezembro de 2012. Dispõe sobre a estruturação do Plano de Carreiras e Cargos de Magistério Federal; sobre a Carreira do Magistério Superior; sobre o Plano de Carreira e Cargos de Magistério do Ensino Básico, Técnico e Tecnológico e sobre o Plano de Carreiras de Magistério do Ensino Básico Federal; sobre a contratação de professores substitutos, visitantes e estrangeiros; sobre a remuneração das Carreiras e Planos Especiais do Instituto Nacional de Estudos e Pesquisas Educacionais Anísio Teixeira e do Fundo Nacional de Desenvolvimento da Educação; altera remuneração do Plano de Cargos Técnico-Administrativos em Educação e dá outras providências. Disponível em: http://www.planalto.gov.br/ccivil_03/_ato2011-2014/2012/lei/112772.htm.

CHAUÍ, Marilena. A Universidade pública sob nova perspectiva. Revista Brasileira de Educação. n. 24, set./ dez. 2003. Disponível em: <www.scielo.br/pdf/rbedu/n24/n24a02.pdf>. Acesso em: 17 jan. 2016.

Escritos sobre a Universidade. São Paulo: Editora UNESP, 2001.

CUNHA, Luiz Antônio. 500 anos de Educação no Brasil. Belo Horizonte: Autêntica, 2000.

FAVERO, Maria de Lourdes Albuquerque. A Universidade no Brasil: das origens a reforma universitária de 1968. Revista Educar, Curitiba, n. 28, p. 17-36, 2006.

GARNICA, Antônio Vicente Marafioti. Notas sobre pesquisa qualitativa e fenomenologia. Interface, Botucatu, v. 1, n. 1, p. 109-122, ago. 1997. Disponível em:

\footnotetext{
${ }^{6}$ A íntegra das referência estão disponíveis no link da tese: https://www.ufjf.br/ppge/files/2019/03/TESEFINAL-Revisada-em-11-5-19-FORMATADA-FINAL-ok.pdf
} 
<http://www.scielo.br/scielo.php?script=sci_arttext\&pid=S1414$32831997000200008 \& \operatorname{lng}=$ en \&nrm=iso

LEMOS, André. Cibercultua como território recombinante. In TRIVINHO, E.; CAZELOTO, E. (Eds.). A cibercultua e seu espelho: campo de conhecimento emergente e nova vivência humana na era da imersão interativa. São Paulo: ABCiber, Instituto Itaú Cultural. 2009. p. 38 46. Disponível em: <http://abciber.org.br/publicacoes/livro1/textos/cibercultua-comoterritorio-recombinante1/>.

LÉVY, Pierre. Cibercultua. (Trad. Carlos Irineu da Costa). São Paulo: Editora 34, 2009.

MASETTO, Marcos T. Competências pedagógicas do professor universitário. 3. ed. São Paulo: Summus, 2015.

NOVOA, Antônio. Entrevista $.7^{\circ}$ SIMPOSIO INTERNACIONAL DE EDUCAÇÃO E COMUNICAÇÃO DA UNIVERSIDADE DE TIRADENTES. 30/09/2016. 9:59'. Disponível em: 〈https://drive.google.com/file/d/0B2cN1lzljWqsLUg3ekJKT2tpU2c/view〉.

. Os professores na virada do milênio: do excesso dos discursos à pobreza das práticas. Educ. Pesqui., São Paulo, v. 25, n. 1, p. 11-20, jun. 1999. Disponível em: $<$ http://www.scielo.br/scielo.php?script=sci_arttext\&pid=S1517$97021999000100002 \& \operatorname{lng}=$ en\&nrm=iso $>$.

(Org.). Vidas de professores. 2. ed. Porto, Portugal: Porto editora, 1995.

PACHANE, Graziela Giusti. A importância da formação pedagógica para o professor universitário: a experiência da UNICAMP. Tese (Doutorado) - Faculdade de Educação, Universidade Estadual de Campinas, Campinas, 2003.

PIMENTA, Selma. Garrido; ANASTASIOU, Lea das Graças Camargo. Docência no ensino superior. 4. ed. São Paulo: Cortez, 2010.

SANTAELLA, Lúcia. Cultura e artes do pós-humano: da cultura das mídias à cibercultua. São Paulo: Paulus, 2003.

Navegar no Ciberespaço: o perfil cognitivo do leitor imersivo São Paulo: Paulus, 2004. Disponível em:

<http://www.insite.pro.br/2010/dezembro/leitor_imersivo_santaella.pdf >. Acesso em: 11 abr. 2017.

SOUZA, Jobeane Franca de. Identidade profissional do docente de licenciatura em ciências biológicas da UFS: desvelando os significados de ser professor. 163 f. Dissertação 
(Mestrado acadêmico em Educação) - Fundação Universidade Federal de Sergipe, São Cristóvão, 2012.

VASCONCELLOS, Maura Maria Morita; SORDI, Maria Regina Lemes. Formar professores universitários: tarefa (im)possível? Interface, Botucatu, SP, v. 20, n. 57, p. 403-414, 2016. Disponível em:

<https://www.scielosp.org/article/ssm/content/raw/?resource_ssm_path=/media/assets/icse/v2 0n57/1807-5762-icse-1807-576220150450.pdf>. Acesso em: 20 mar. 2018.

VASCONCELLOS, Vanessa Alves da Silveira De. Pedagogia Universitária: O Programa Ciclus e as Significações Imaginárias na Formação Continuada de Professores Universitários. 182 f. Dissertação (Mestrado Acadêmico em Educação) - Universidade Federal de Santa Maria, 2011.

VEIGA, Ilma Passos Alescastro; et al. Universidade e desenvolvimento profissional docente: propostas em debate. Araraquara, SP: Junqueira \& Marin, 2012.

ZABALZA, Miguel Angel Beraza. O ensino universitário: Seu cenário e seus protagonistas. Porto Alegre: Artmed, 2004.

Palestra: Competências Docentes. Conferencia pronunciada Universidad de Santiago de Compostela, Espanha, 9 fev. 2005.

Este é um artigo de acesso aberto distribuído sob os termos da Licença Creative Commons Atribuição Não Comercial-Compartilha Igual (CC BYNC-4.0), que permite uso, distribuição e reprodução para fins não comerciais, com a citação dos autores e da fonte original e sob a mesma licença. 